\title{
Food Safety and Hygienic Practices Among Food Vendors in Egbeda Local Government Area, Ibadan Oyo State
}

\author{
ADEBAYO O. O* OYETOLA, B. T \\ Department of Agricultural Extension And Rural Development, Ladoke Akintola University of Technology, \\ Ogbomoso, Oyo state, Nigeria
}

\begin{abstract}
The aim of the study is to analyse food safety and hygiene practices among food vendors in Egbeda local government area of Oyo state. Well-structured questionnaire was used with an interview schedule to obtain relevant information from 120 respondents. The respondents were selected through purposive sampling technique. The data for this study were analyzed using both descriptive and inferential statistics. The descriptive statistics that were used include frequency counts, percentage, mean. The inferential statistics include Pearson product moment correlation (PPMC).The results that $80 \%$ of the respondents were female with mean years of 37 . Also their highest literacy level was secondary education. Majority (80\%) are married with household size of 5 members, majority prepare ready to eat food, majority $(57.5 \%)$ are experienced and above average $(55.8 \%)$ had training in food service, majority of the respondent $(95.8 \%)$ had personal savings as their major source of income and $55 \%$ of the respondents are Christians. The results showed that $66.7 \%$ of the respondents were involved in food trade as their primary occupation. The result also revealed that some of the selected socio-economic variables such as age $\left(x=0.248^{* *} ; \mathrm{p} \leq 0.06\right)$, years of experience $(\mathrm{x}=0.349 * * ; \mathrm{p} \leq 0.000)$ respectively exhibited significant relationship with the respondent knowledge of food safety and hygiene practices. It was recommended that food vendors should use personal protective equipment (like nose/face mask, apron) during food preparation, Government should provide water source (tap water) to solve the inadequacy of water supply faced by the respondents. The study concluded that majority had knowledge of food safety and hygiene and practice good food safety and hygiene.
\end{abstract}

Keywords: food safety, Hygiene, Analysis, vendor

DOI: $10.7176 / \mathrm{FSQM} / 109-02$

Publication date:June $30^{\text {th }} 2021$

\section{Introduction}

Food safety has received much emphasis by agencies worldwide to the threat of contradicting food borne illnesses. Food safety is receiving heightened attention worldwide as the important links between food and health are increasingly recognized. Improving food safety is an essential element of improving food security which exists when populations have access to sufficient and healthy food. At the same time, as food trade expands throughout the world, food safety has become a shared concern across the globe, policies were made to address food safety issues to reduce risk and spread of food borne diseases (Unnevehr et al 2002).Food borne illnesses cover a wide range of diseases and are a growing public health concern which has caused morbidity and mortality worldwide. Food borne illnesses occurs as a result of consuming food contaminated with microorganism or their toxins through unhygienic practices (Bas, Ersun and Kwanc 2016; WHO 2007).

Food safety, according to Scallan et al (2011) are the conditions and measures that are necessary along the food production chain to ensure that it is safe and fit for consumption. Food is considered safe when it is free from chemical, biological and physical hazards that may result in illness or even death to the consumer, making food safety a concern as it poses risk to the population especially to the vulnerable groups such as infants, young children, elderly individuals and those with immunodeficiency disorder (Soon, Singh and Barns 2011). The measurement of the safety of foods has relied on evaluation of the microbiological quality of foods (Havelaar et al 2010).

The majority of foodborne outbreaks associated with food vendors have involved transmission of the pathogens to food by the food vendors' hand (Cakiroglu and Ucar 2008) and ensuring personal hygiene particularly hand washing has been cited the most effective tool in preventing the spread of foodborne infections (NHS plus, 2008) Food establishment are vital for development of city and town in meeting the demand of the people (Fellows and Hilmi, 2011). Lack of personal hygiene among food vendors is one of the most commonly reported practices that contribute to foodborne illness (Taulo et al 2009). Developing and educating a workforce knowledgeable in food safety and hygiene is necessary to improve food safety in food service establishments. Studies of the knowledge, attitudes and practices of food vendors in developing countries have been conducted and several trends have been reported in this workforce. Factors that were associated with better food safety and hygiene include the level of education of the vendors and training in food service (Zeru and Kumie, 2007). Training programs are effective and improved environmental and worker hygiene practices in a study of fast 
food and food vendors in Nigeria (Olumankaiye and Bakare, 2013). However, despite knowledge of safe food vending methods, several studies have found that food vendors often do not use safe food vending practices based on the observation and microbial food testing (Bas et al, 2006).

People died from eating local food known as Fate at Shyar Ajiya in Zamfara, this was blamed on the handling process in the preparation of the leaf porridge. Therefore, the food safety and hygiene practices among food vendors in the community are often implicated when food disease outbreak occurs. The World Health Organization estimated that in developing countries, up to $30 \%$ of the populations suffer from foodborne diseases each year, whereas in developing countries up to 2million deaths are estimated per year (WHO, 2015). It is based on these problems highlighted that the research will be conducted in other to analyse food safety and hygiene practices among food vendors toward ensuring food safety and hygiene for the consumers in Egbeda local government area.

Food is life. In Abraham Maslow's hierarchy of needs, the most important need after life is the requirement for food. The American psychologist could not have been more accurate in his conceptualization of a hierarchy of human needs (Maslow 1943, 1954). Food is any substance consumed to provide nutritional support to the body, it is usually of plant or animal origin and contains essential nutrients such as carbohydrates, proteins, fats, vitamins, minerals and water (Encyclopedia 2020).

Food safety is a scientific discipline describing handling, preparation, and storage of food in ways that prevent food borne illness. This can also be described as a condition achieved by series of actions including processing, handling, storage and preparation aimed at ensuring that all food are safe as possible, reducing health hazards and preventing food poisoning and food borne illness. The goal of food safety monitoring is to keep food wholesome. This involves the protection of the food supply from microbial, chemical and physical hazards or contamination that occurs during all stages of food production, processing, preparation (WHO 2002).

Good food hygiene is an important practice that we need to observe to ensure our food is safe for consumption, without this healthy practice, harmful germs that cause food poisoning can spread very easily during food preparation process, it is therefore our full responsibility to keep the food that we and our loved ones eat very clean and safe during and after preparation on a daily basis (WHO 2016). Hygiene deals with the promotion and presentation of health while food hygiene is all conditions that measure the safety and suitability of food at all stages of food chain (WHO 2016).Good food hygiene by food vendors is essential to ensure that the foods prepared are safe. Poor hygiene procedures can put the community at risk. To achieve good hygiene, food vendors need to consider their actions during the entire food process from the moment the raw food ingredients are purchased to the final stage before it is consumed (HIA 2012). food.

Hospitality Institute of Australasia in 2012 identified hygiene measures to ensure the non-contamination of

A major cause of food poisoning is the lack of personal hygiene practiced by food vendors. Food vendors must be aware that they themselves, their actions, their health and their personal habits have a great impact on the wholesomeness of food served to the public. As with many aspects of control in other areas, all personal hygiene requirements and regulations must be abided by: failure to follow just one rule can (and has) led to massive outbreaks of food poisoning causing not only loss of trade and jobs at the venue, but also deaths in the community especially among the very young, the very old, and the very weak. Personal hygiene is a serious issue and must be treated as such: the industry simply cannot afford to tolerate workers who treat it as a joke. You are regarded by patrons and your employer as a professional and you must therefore know what is expected, cub sound work practices, and be vigilant in ensuring regulations are complied with (HIA 2012).

Egan et al (2007) suggest that food safety training should be conducted at the workplace with increased training hours which would result in improvement in food safety and hygienic practices and that effective food hygiene training needs to target changing behaviors of food vendors with constant evaluation.

Musa et al (2003) investigated food hygiene practice of food vendors in Ilorin kwara state Nigeria. The researchers observed that the major unhygienic practices observed among the food vendors were poor care of used utensils, use of previously used water for washing and cleaning, lack of covering apron among food vendors. Only $85(46 \%)$ of the respondents used soap and water to clean their utensils while the rest $100(54 \%)$ used unhygienic methods to clean their utensils. It was observed that the food vendors who used soap and water for cleaning at locations are relatively closer to water source compared to other food vendors who used other methods to clean their utensils. Unkempt fingernails, skin lesions and poor food protection from flies were some of the food contaminating risk factors observed in the study.

The knowledge of food vendors about the food and safety practices is an important concern in any country (Akabande et al 2017). The importance of food safety and hygiene knowledge among food vendors have been assessed in past studies around the world (Abdul-Mutslib et al, 2012, Bas et al, 2006). Having good knowledge and practices towards food safety plays a very important role to determine the safety of products disregard to any food service establishments one is working with (Al- shabib, Moslihey \& H\usain 2015).

Food safety knowledge is largely obtained through training in food safety, this includes attending certified 
training course where participants were exposed on the importance of time-temperature control, personal hygiene, safe food handling and causes of foodborne illnesses. Other sources of food safety knowledge are from printed education materials and the use of new media where information on food safety can be found at the tip of the finger. In order to have good food vending practices, the food vendors must be trained and have knowledge in food safety. Some studies have shown that increased knowledge on food safety will result in positive food vending practices (Abdul Mutalib et al 2012). However there are also studies that show that having good level of knowledge did not always result in positive behavior towards hygienic practices (Akabande et al 2017). In line with the above background, the study determined the socio-economic characteristics of food vendors, identified food safety and hygiene practices of the respondents, ascertain the knowledge of safety and hygiene practices among food vendors and identified factors influencing food vending in the study area.

Certain food safety hazards are closely linked with sanitation, water supply, food preparation and food marketing (Geneva 2002, WHO 2002). Water is a major input in food, from primary production through all stages in the food value chain to consumption. Water can contact food directly or indirectly and is used in maintenance of hygiene and sanitation throughout the food chain. Water is a diminishing resource globally and not all food primary producers and processors have access to safe water sources. Water needs to be used conservatively and it is possible to reuse water if it does not present a health risk for consumers (WHO 2017).

There will always be some waste products that cannot be utilized, no matter how cost conscience a business may be. These include product packaging, rotted foodstuffs, fats and some trimmings. These waste products need to be disposed of in a safe and environmentally responsible manner to prevent pests, unwanted odours and bacterial growth (HIA 2012).

\section{Methodology}

The sample size was based on 120 respondents in the study area. The research was carried out using purposive sampling in selection of respondents from four (4) wards (Egbeda, olode/Alakia, olodo III, olodo/Kumapayi) out of 11 wards in the study area because of the concentration of food vending.

The data for this study was obtained from primary source with the aid of structured interview schedule. The schedule was divided into sections which are designed in line with the objectives of the research work. Questions was asked and used for collecting data during the interview schedule section. The study make use of both descriptive and inferential statistical tools. This being presented with the aid of frequency chart, mean and percentage table will be used to describe the socio-economic characteristics of the respondent while the Pearson Product Moment Correlation (PPMC) analysis was used to determine the relationship between the knowledge of food safety and hygiene on food safety and hygiene practices.

\section{Results AND DISCUSSION}

\subsection{Socio-economic characteristics of the respondents}

About $(35.8 \%)$ of the respondents were between the age range of $21-30$ years, $22.5 \%$ were between the age of $31-40$ years, $24.2 \%$ were between the ages of $41-50$ years while $15 \%$ were between the age range of 51-60years while $2.5 \%$ of the respondents were above 60 years . The mean age of the respondents was 36 . The results showed that half $(58.3 \%)$ of the respondents were between the age range of 21-40years, this implies that most of the respondents are still in their active age. This is expected to significantly influence their food safety and hygiene practices. This is consistent with Woh et al; 2016 who observed that age significantly influenced food safety knowledge and Anuradha et al; 2014, who detected that age significantly influenced respondents' attitudes towards food safety and hygiene practices

Majority $(80 \%)$ of the respondents were female and $20 \%$ were male. The study reveals that food vending was dominated by females, which may be because it is perceived as women's occupation. This agrees with findings from Lues et al who found food vending to be a common income generating venture particularly for women in developing countries.

Majority $(62.5 \%)$ of the respondents were married and living with their husband at the time of the survey. This indicate that majority of the respondents were married. This implies that majority of the respondents in the study area have additional responsibilities to their spouses and children.

Majority $(80 \%)$ of the respondents had household size between 4-6 members which is the highest percentage, followed by household size between 7-9 members and 1-3 members which had $11.7 \%$ and $8.3 \%$ respectively, the mean household size of the respondents was 5 members. This may affect respondents' food safety and hygiene practices as large household size may impair their food safety and hygiene practices.

Majority $(66.7 \%)$ of the respondents were involved in food trade as their primary occupation, $16.7 \%$ were artisans and $12.5 \%$ were civil servants while $4.1 \%$ had farming as their primary occupation. This implies that majority of the respondents had food trade as their primary occupation which is expected to positively influence their food safety practices as more concentration will be on the food vending services.

Majority (55\%) of the respondents in the study area were Christians while $45 \%$ are Muslims. This implies 
that both religion is not bias to food vending in the study area. The study did not found any statistically significant relationship between the respondents' religion and their food safety and hygiene practices.

Majority (96.2\%) of the respondents had formal education viz a viz, 30\% had primary education, $37 \%$ had secondary education and $29.2 \%$ had tertiary education while $3.3 \%$ had no education. This implies that majority of the respondents are literate. Since majority of the respondents were literate, there is tendency that they have understanding of food safety and hygiene practices. This is in line with WHO 1996, education has been reported to play a key role in increasing the food safety knowledge of food vendors, thus improving their attitudes towards food safety and hygiene

Above average $(55.8 \%$ ) of the respondents had training in food service while $44.2 \%$ had no training in food service. It was observed that majority that had training in food service had the training in the same training center such as Iyadunni food training, police food service training. This implies that the trained will be certified and will be able to put to practice the knowledge acquired. This is in line with the statement; knowledge which acquired through training is essential in food safety as it shown to increase food vendor's knowledge of proper food safety and hygiene practices (Park et al., 2010; Afolaranmi et al., 2014). One of the possible reasons why the minority has no training in food service is; since food preparation and handling can be learnt informally, acquiring a training may not have appreciable effects on the outcome of food safety.

Majority (95.8\%) of the respondents had personal savings as their major source of income capital, $2.5 \% \mathrm{had}$ co-operative as their major source of income capital and $0.8 \%$ had friends and relatives while $0.8 \%$ had bank loan. This implies that majority of the respondent solely depend on a stream of income which is expected to decide the capability of the respondents to acquire materials and equipment needed to practice food safety and hygiene, in which insufficient capital will impair food safety and hygiene practices.

\subsection{Food safety and hygiene practices}

Based on the analysis for personal hygiene, wash of hand after using toilet ranked $1^{\text {st }}$ with WMS=2.86, Use of apron, rank $2^{\text {nd }}$ with $\mathrm{WMS}=2.85$, Covers food to disallow flies contact rank $3^{\text {rd }}$ with $\mathrm{WMS}=2.61$, Staying off work when sick rank $4^{\text {th }}$ with $\mathrm{WMS}=2.47$, Covering of wound and cut when handling food rank $5^{\text {th }}$ with $\mathrm{WMS}=2.38$, Covers hair while cooking and vending rank $6^{\text {th }}$ with $\mathrm{WMS}=2.33$, medical screening rank $7^{\text {th }}$ with $\mathrm{WMS}=2.28$, Sanitizing utensils before and after use rank $8^{\text {th }}$ with $\mathrm{WMS}=1.96$, use gloves, blow air into the polythene bag before use rank $9^{\text {th }}$ with $\mathrm{WMS}=1.21$ while Chewing stick while vending rank $10^{\text {th }}$ with WMS $=0.83$ The study revealed that majority (91.7\%) respondents wash their hand after using toilet, this shows that respondents were conscious of their practices to ensure safe food. Also majority of the respondents use apron, covers food to disallow flies contact, stay off work when sick indicates that the respondent practices personal hygiene. The study indicates that most of the respondents do not blow air into the polythene bag before use, this practice can prevent transfer of air borne pathogens. Majority of the respondent do not chew stick while vending food, this practice will prevent food contamination. Based on the analysis of waste disposal, daily waste disposal rank $1^{\text {st }}$ with $\mathrm{WMS}=3.00$, twice weekly and weekly rank $2^{\text {nd }}$ with $\mathrm{WMS}=0.31$, this indicates that most of the respondent practice daily waste disposal which will prevent harboring food borne pathogen and food contamination through flies and other insects.

Based on the analysis of water supply, well water rank $1^{\text {st }}$ with $\mathrm{WMS}=2.81$, borehole $\operatorname{rank} 2^{\text {nd }}$ with $\mathrm{WMS}=2.43$,tap water rank $3^{\text {rd }}$ with $\mathrm{WMS}=0.44$,rain rank $4^{\text {th }}$ with $\mathrm{WMS}=0,20$ while stream rank $5^{\text {th }}$ with $\mathrm{WMS}=0$,this indicate that most of the respondent use well water and borehole as their source of water supply, this will provide quality water for vending activities thereby ensure food safety, it was observed that none of the respondent use stream as their source of water supply, as stream is known to be full of contaminations which could lead to food contamination if used in vending services.

Based on analysis of conditions of food, wash food before cooking rank $1^{\text {st }}$ with WMS $=3.00$, reuse of oil for frying rank $2^{\text {nd }}$ with $\mathrm{WMS}=2.76$ while food eating before serving rank $3^{\text {rd }}$ with $\mathrm{WMS}=0$. This indicates that most of the respondent wash food before cooking, this will remove dirt and make the food contaminant free.

Based on the analysis of clean environment when food is stored, in refrigerator rank $1^{\text {st }}$ with $\mathrm{WMS}=3.00$, plastic container rank $2^{\text {nd }}$ with $\mathrm{WMS}=2.92$, cupboards rank $3^{\text {rd }}$ with $\mathrm{WMS}=2.84$ while in an open space rank $4^{\text {th }}$ with WMS $=0.44$. This revealed that most of the respondent kept a clean environment when food is stored. This implies that the vendors have good safety and hygiene practices, this is similar to the findings by Tan et al. (2013) and Yardimici et al. (2015).

\subsection{Knowledge of food safety and hygiene practices}

The knowledge identified are based on personal hygiene; Staying off work when sick is ideal to prevent food contamination (WMS $=4.88$ ) which is ranked $1^{\text {st }}$, Washing of hand after toilet is an ideal practice for food safety rank $2^{\text {nd }}$ with $\mathrm{WMS}=4.72$, Covering of food to disallow flies contact is a necessary practice in food vending rank $3^{\text {rd }}$ with $\mathrm{WMS}=4.68$, Washing of fruit before eating rid the fruit of any pathogen rank $4^{\text {th }}$ with $\mathrm{WMS}=4.57$, Use of apron in food vending is necessary rank $5^{\text {th }}$ with $\mathrm{WMS}=4.48$ Handling food with bare hand could lead to food 
contamination rank $6^{\text {th }}$ with $\mathrm{WMS}=4.39$. The study revealed that majority of the respondent acknowledged that staying off work when sick is ideal to prevent food contamination also washing of hand after toilet is an ideal practice for food safety, this indicates that the respondent had knowledge about food safety and hygiene.

Knowledge identified based on conditions of food; Food-borne disease can result from storing raw meat and cooked foods in the same refrigerator rank ${ }^{1 \text { st }}$ with $\mathrm{WMS}=4.38$, Washing of food before cooking is important in food preparation rank $2^{\text {nd }}$ with $\mathrm{WMS}=4.37$, Reuse of oil for frying is not safe in food vending rank $3^{\text {rd }}$ with $\mathrm{WMS}=3.56$, The safest way to defrost frozen meat is to keep it at room temperature during the night rank $4^{\text {th }}$ with WMS=3.29, this indicates that most of the respondent will not store raw meat and cooked food together in the same refrigerator having the knowledge that it can result to food borne disease and most $(40 \%) 0$ f the respondent considered reuse of oil for frying not safe in food vending, this knowledge will propel food safety and hygiene practice.

Knowledge identified based waste disposal; Waste should be disposes daily rank $1^{\text {st }}$ with $\mathrm{WMS}=4.88$, Waste should be disposed weekly rank $2^{\text {nd }}$ with $\mathrm{WMS}=2.02$, Waste should be disposed twice weekly rank $3^{\text {rd }}$ with WMS=1.65.the study revealed that all the respondent dispose waste daily this prevent harboring pest and ensure serene environment.

Knowledge identified bases on clean environment; Food -borne disease can result from storing raw meat and cooked food in the same refrigerator rank $1^{\text {st }}$ with $\mathrm{WMS}=4.48$ while food safety and hygiene practices will be better when all vendors comply with environmental health rules rank $2^{\text {nd }}$ with WMS $=4.37$.

It was observed that staying off work when sick is ideal to prevent food contamination, waste should be disposed daily, washing of hand after toilet is ideal for food safety, washing of food before cooking, were mostly indicated as the respondents' knowledge of food safety, this knowledge being practices will positively influence food safety as well as consumers' safety. It was observed that the respondents indicated that Covering of food to disallow flies contact is a necessary practice in food vending and majority strongly agree that food-borne disease can result from storing raw meat and cooked foods in the same refrigerator which indicates that the respondent will ensure proper food storage, this will positively affect food safety and hygiene practices. This implies that the respondents had knowledge of food safety and hygiene practices. This is consistent with the study by Bas, Ersun and Kivanc (2006), Abdul-Mutalib et al.(2012), Tan et al (2013) and Stenger et al.(2014) that showed good food vendors knowledge in food safety and hygiene practices in food operation and catering.

\subsection{Factors affecting food safety and hygiene practices}

The factors are food vending location, inadequate water supply, inadequate storage facilities, insufficient capital, vendors' health status, high cost of food items, level of hygiene knowledge, cultural belief. This implies that vending location, will have significant impact on food safety and hygiene. Inadequate water supply can lead to reuse of water which could impair food safety and hygiene also inadequate storage facilities will negatively affect food safety and hygiene practices.

\subsection{Test of hypothesis}

The hypothesis was stated as follows:

HO: there is no significant relationship between the selected socio-economic characteristics of the respondents and food safety and hygiene practices.

For this hypothesis, Pearson Product Moment Correlation was used to test for the significant relationship between the selected socio economic characteristics and food safety and hygiene practices. The result of the analysis revealed that some of the selected socio-economic variables such as age $\left(x=0.248^{* *} ; \mathrm{p} \leq 0.06\right)$, years of experience $\left(x=0.349^{* *} ; \mathrm{p} \leq 0.000\right)$ respectively exhibited significant relationship with food safety and hygiene practices. Increase in age will result to effective food safety and hygiene practices as increase in age is associated to increase in knowledge and attitude ,also as the respondents increase in experience they acquire better vending skills, attitudes which aid effective food safety and hygiene practices.

Therefore the results implies that all the above socio economic characteristics have decisive influence on the dependent variable. Therefore the null hypothesis is hereby rejected, hence, the alternative hypothesis is accepted.

HA; there is significant relationship between the socio economic characteristics and the knowledge of food safety and hygiene practices. 
Table 1: Distribution of respondents according to their socio-economic characteristics

\begin{tabular}{|c|c|c|c|}
\hline Characteristics & Frequency & Percentage & Mean \\
\hline \multicolumn{4}{|l|}{ Age in years } \\
\hline $21-30$ & 43 & 35.8 & 36.95 \\
\hline $31-40$ & 27 & 22.5 & \\
\hline $41-50$ & 29 & 24.2 & \\
\hline $51-60$ & 18 & 15 & \\
\hline$>60$ & 3 & 2.5 & \\
\hline \multicolumn{4}{|l|}{$\operatorname{Sex}$} \\
\hline Male & 24 & 20 & \\
\hline Female & 96 & 80 & \\
\hline \multicolumn{4}{|l|}{ Marital status } \\
\hline Married & 75 & 62.5 & \\
\hline Single & 45 & 37.5 & \\
\hline \multicolumn{4}{|l|}{ Household size } \\
\hline $1-3$ & 10 & 8.3 & \\
\hline $4-6$ & 96 & 80 & \\
\hline $7-9$ & 14 & 11.7 & 5 \\
\hline \multicolumn{4}{|l|}{ Religion } \\
\hline Christianity & 66 & 55 & \\
\hline Islam & 54 & 45 & \\
\hline \multicolumn{4}{|c|}{ Level of education } \\
\hline No education & 4 & 3.3 & \\
\hline Primary & 36 & 30 & \\
\hline secondary & 45 & 37.5 & \\
\hline Tertiary & 35 & 29.2 & \\
\hline \multicolumn{4}{|c|}{ Primary occupation } \\
\hline Farming & 5 & 4.1 & \\
\hline Trading & 80 & 66.7 & \\
\hline Civil servant & 15 & 12.5 & \\
\hline Artisan & 20 & 16.7 & \\
\hline \multicolumn{4}{|c|}{ Training in food service } \\
\hline Yes & 67 & 55.8 & \\
\hline No & 53 & 44.2 & \\
\hline
\end{tabular}

Source; field survey 2020.

Table 2: Distribution of respondents by food safety and hygiene practices Frequency(percentage) Level of occurrence

\begin{tabular}{|c|c|c|c|c|c|c|}
\hline Food safety and hygiene practices & Always & Often & Seldom & Never & WMS & Rank \\
\hline \multicolumn{7}{|l|}{ Personal hygiene } \\
\hline Wash hand after using toilet. & $110(91.7)$ & $6(5.0)$ & - & $4(3.3)$ & 2.86 & $1^{\text {st }}$ \\
\hline Use of apron. & $109(90.8)$ & $5(4.2)$ & - & $6(5.0)$ & 2.85 & $2^{\text {nd }}$ \\
\hline Covers food to disallow flies contact & $101(84.2)$ & $5(4.2)$ & - & $14(11.7)$ & 2.61 & $3^{\text {rd }}$ \\
\hline Staying off work when sick. & $84(70.0)$ & $19(15.8)$ & $6(5.0)$ & $11(9.2)$ & 2.47 & $4^{\text {th }}$ \\
\hline Covering of wound and cut when handling food. & $85(70.8)$ & $11(9.2)$ & $9(7.5)$ & $15(12.5)$ & 2.38 & $5^{\text {th }}$ \\
\hline Covers hair while cooking and vending. & $76(63.3)$ & $24(20)$ & $3(2.5)$ & $17(14.2)$ & 2.33 & $6^{\text {th }}$ \\
\hline Medical screening. & $75(62.5)$ & $23(19.2)$ & $2(1.7)$ & $20(16.7)$ & 2.28 & $7^{\text {th }}$ \\
\hline Sanitizing utensils before and after use. & $70(58.3)$ & $12(10.0)$ & $1(0.8)$ & $37(30.8)$ & 1.96 & $8^{\text {th }}$ \\
\hline Blow air into the polythene bag before use. & $38(31.7)$ & $12(10)$ & $7(5.8)$ & $63(52.5)$ & 1.21 & $9^{\text {th }}$ \\
\hline Chewing stick while vending & $25(20.8)$ & $11(9.2)$ & $3(2.5)$ & $81(67.5)$ & 0.83 & $10^{\text {th }}$ \\
\hline \multicolumn{7}{|l|}{ Waste disposal } \\
\hline Daily. & $120(100)$ & - & - & - & 3.00 & $1^{\text {st }}$ \\
\hline Twice weekly. & - & $7(5.8)$ & $23(19.2)$ & $81(67.5)$ & 0.31 & $2^{\text {nd }}$ \\
\hline Weekly. & - & $6(5.0)$ & $25(20.8)$ & $89(74.2)$ & 0.31 & $2^{\text {nd }}$ \\
\hline \multicolumn{7}{|l|}{ Water supply } \\
\hline Well water & $100(83.3)$ & $17(14.2)$ & $3(2.5)$ & - & 2.81 & $1^{\text {st }}$ \\
\hline Borehole & $85(70.8)$ & $11(9.2)$ & $15(12.5)$ & $9(7.5)$ & 2.43 & $2^{\text {nd }}$ \\
\hline
\end{tabular}




\begin{tabular}{|c|c|c|c|c|c|c|}
\hline Tap water & - & $25(20.8)$ & $3(2.5)$ & $92(76.7)$ & 0.44 & $3^{\text {rd }}$ \\
\hline Rain & - & - & $24(20)$ & $96(80)$ & 0.2 & $4^{\text {th }}$ \\
\hline Stream & - & - & - & $120(100)$ & 0 & $5^{\text {th }}$ \\
\hline \multicolumn{7}{|l|}{ Conditions of food } \\
\hline Wash food before cooking & $120(100)$ & - & - & - & 3.00 & $1^{\text {st }}$ \\
\hline Reuse of oil for frying & $100(83.3)$ & $16(13.3)$ & - & $4(3.3)$ & 2.76 & $2^{\text {nd }}$ \\
\hline Food eating before serving & - & - & - & $120(100)$ & 0 & $3^{\text {rd }}$ \\
\hline \multicolumn{7}{|c|}{ Clean environment when food is stored } \\
\hline In refrigerator & $120(100)$ & - & - & - & 3.00 & $1^{\text {st }}$ \\
\hline Plastic container & $110(91.7)$ & $10(8.3)$ & - & - & 2.92 & $2^{\text {nd }}$ \\
\hline Cupboards & $101(84.2)$ & $19(15.8)$ & - & - & 2.84 & $3^{\text {rd }}$ \\
\hline In an open space & $84(70)$ & $19(15.8)$ & $6(5.0)$ & $11(9.2)$ & 2.47 & $4^{\text {th }}$ \\
\hline
\end{tabular}

Source: field survey 2020

Figures: brackets are percentage

WMS: weighted means score

Table 3: Distribution of respondent according to knowledge of food safety and hygiene practices

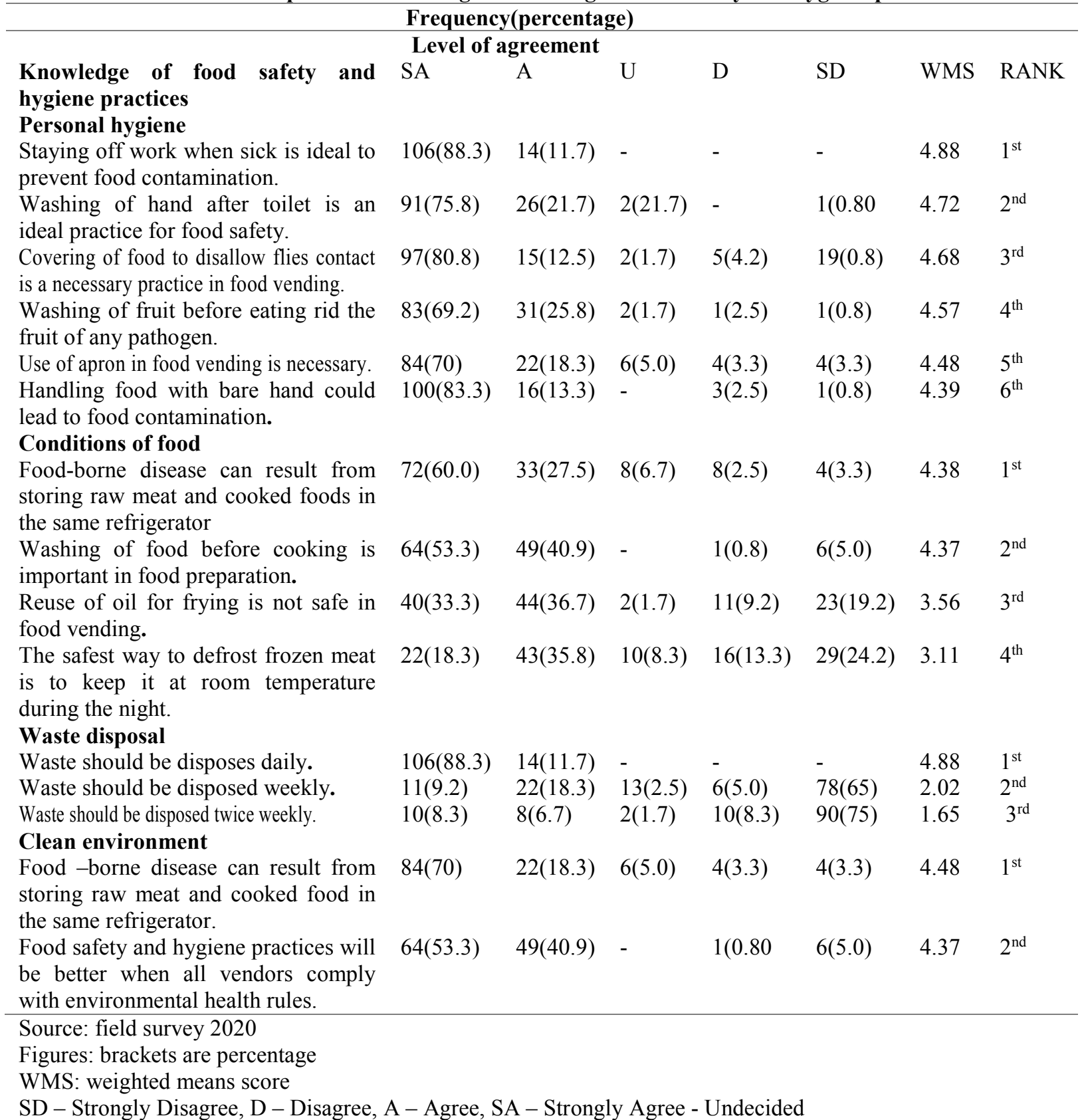


Table 4: Distribution of respondents by factors affecting food safety and hygiene practices

Factors affecting food safety and hygiene practices

$\begin{array}{lc}\text { Food vending location } & 114(95.0) \\ \text { Inadequate water supply } & 114(95.0) \\ \text { Inadequate storage facilities } & 110(91.7) \\ \text { Level of hygienic knowledge } & 96(80) \\ \text { Vendors health status } & 69(57.5) \\ \text { Insufficient capital } & 49(40.8) \\ \text { High cost of food items } & 40(33.3) \\ \text { Cultural belief } & 19(40.8)\end{array}$

Source: field survey 2020.

*multiple response

Table 5: Summary of Pearson Product Moment Correlation analysis showing relationship between the selected socio economic characteristics of the respondents and food safety and hygienic practices.

\begin{tabular}{|c|c|c|c|c|}
\hline Variables & $\begin{array}{l}\text { Correlation } \\
\text { coefficient(r) }\end{array}$ & $P$ - value & Decision & Remark \\
\hline Age & $0.248 * *$ & 0.006 & $\mathrm{~S}$ & Reject Ho \\
\hline Household size & 0.177 & 0.053 & NS & Accept Ho \\
\hline Years & $0.349 * *$ & 0.000 & $\mathrm{~S}$ & Reject Ho \\
\hline
\end{tabular}

experience

** Correlation is significant at the 0.01 level (2-tailed)

Source: Field survey, 2020

$\mathrm{S}=$ Significant, NS = Not significant, Ho: Null hypothesis

\section{Conclusion and recommendations}

Based on the results of the findings, the study shows that the respondents were within their economically active age group with the mean age 36.95 which significantly influence their food safety and hygiene practice and years of experience of the respondents is positively significant to their food safety and hygiene practice. Majority of the respondent were females and were married. Most of the respondent are not opportune to have another source of income which could enhance their vending activities, apart from their personal savings. The most felt factors affecting food safety and hygiene practice is food vending location. However majority had knowledge of food safety and hygiene and good food safety and hygiene practice.

The following recommendations were made based on the findings of the study

- Food vendors should use personal protective equipment (like nose/face mask, apron) during food preparation.

- Government should provide water source to solve the inadequacy of water supply faced by the respondents.

- Government through media agencies should provide awareness on the benefits and danger of food safety and hygiene practices in the study area.

\section{References}

Abdul-Mutalib,N.A.,Syafinaz ,A.N.,Sakai,K.,\& Shirai,Y.(2015).An overview of foodborne illness and food society in Malaysia. International Food Research Journal, 22(3), 896-901

Akabanda ,F., Hlotsi, E.H., \& Owusu-Kwateng, J (2017). Food safety knowledge, attitudes and practices of institutional food handlers in Ghana.

Anuradha M, Dandekar R (2014). Knowledge, attitude and practices among food handlers in food borne diseases: A hospital based study in tertiary care Hospital

Bas, M., Ersun ,A.S.,\& Kivanc, G.(2006). The evaluation of food hygiene knowledge, attitude and practices of food handlers in food businesses in turkey. Food control,17(4),317-322

Carkiroglu and Ucar ,2008: employers perception of hygiene in the catering industry Ankara, Turkey, food control 19:9-15

Egan, M.B., Raats, M.M., Grubb,S.M., Eves,A., Lumbers M.L., Dean, M.S.\& Adams, M.R.(2007).A review of food safety and food hygiene training studies on the commercial sector. Food control,18(10);1180-1190

Encyclopaedia 2020. www. Britannica.com; definition of food.

Fellows, P.\&Hilmi,M.(2011).FAO Diversification booklet number 18;selling street and snack foods. Rome infrastructure and Agro-industries Division food and Agriculture Organization of the United Nations

Havelaar AH, Brul S, De Junge A, De jonge R, Zwiettering MH. Terkunle BH (2010).Future challenges to 
microbial food safety. International journals, food microbial 139:579-594 .

Hospitality institute of Australisia 2012; basic food safety practices

L. unnevehr and T. Roberts : Food safety incentives on a changing world food system: journals of food control (march 2002)

Lues,J.F.R: Rasepjei, M.R.;venter,p.; Assessing food safety and associatyed food handling practices in street food vending .international journals ,Environmental Health RES 2006,16,319-328.

Maslow (1943); Maslow's Hierarchy of needs.www.simplyphychology.org

Musa, O.I.,\&Akande,T.M.(2003). Food hygiene practices of food vendors in the secondary schools in ilorin. The Nigerian postgraduate Medical Journal, 10(3), 192-196.

NHS Plus (2008). Royal college of physicians, faculty of occupational medicine. Infected Food handlers; occupational aspect of management.

Olumankaiye M F, Bakare K O (2013) Training of food providers for improved environmental conditions of food service outlets in urban area Nigeria.

Scallan,E.,Hoekstra,R.M.,Angulo,F.J.,Tauxe,R.V.,Widdowson,M.A.,ROY,S.L.,Griffin,P.M(2011).Foodborne illness acquired in the united states - major pathogens.

Soon, J.M., Singh, H., \& Baines, R. (2011).Foodborne disease in Malaysia; A review .Food control, 22(6), 823830

Taulo S, Wetlesen A, Abrahamsen R k, Narvhus J A, Mkakosya R (2009). Quantification and variability of Escherichia coli and Staphylococcus aureus cross contamination during serving and consumption of cooked thick porridge in Lungwena rural household, Malawi.

Woh PY, Thong KL, Behnke JM, Lewis JW,Zain SNM. Evaluation of basic knowledge on food safety and food handling practices among migrant food handlers in Peninsular Malaysia. Food control .2016:70;64-75.

WHO (2017); guidelines for drinking water quality.

Zeru K, Kumie A (2007); sanitary conditions of food establishments in Mekelle town, Tigray, North Ethiopia. 